\title{
Ischemic Priapism Progressing to Penile Gangrene in a Patient with COVID-19 Infection: A Case Report with Literature Review
}

\author{
Saad M. Alsaedi $\mathbb{D}^{1},{ }^{1}$ Rakan M. Alsarwani ${ }^{(D)},{ }^{1}$ Ahmed I. Ali, ${ }^{2}$ and Saleem A. Aladhrai ${ }^{3}{ }^{3}$ \\ ${ }^{1}$ College of Medicine, Umm Al-Qura University, Makkah, Saudi Arabia \\ ${ }^{2}$ Department of Urology, Security Forces Hospital Program, Makkah, Saudi Arabia \\ ${ }^{3}$ Department of Emergency Medicine, Security Forces Hospital Program, Makkah, Saudi Arabia
}

Correspondence should be addressed to Rakan M. Alsarwani; rakansi@outlook.sa

Received 27 October 2021; Revised 16 January 2022; Accepted 26 January 2022; Published 8 February 2022

Academic Editor: Bruno Megarbane

Copyright (C) 2022 Saad M. Alsaedi et al. This is an open access article distributed under the Creative Commons Attribution License, which permits unrestricted use, distribution, and reproduction in any medium, provided the original work is properly cited.

\begin{abstract}
Priapism is considered a rare disorder and even more rare when it occurs as a complication of COVID-19. To the best of our knowledge, only eight studies have reported priapism as a complication of COVID-19. Here, we report the case of a 66-year-old male with COVID-19 who presented with neglected priapism for three days. On local examination, penile erection was apparent in association with blackened areas on the glans penis extending to the midpenile shaft denoting penile gangrene. A clear line of demarcation was noticed at the midpenile shaft. Penile duplex was performed, showing no blood flow in both cavernosal arteries. Penile aspiration was performed, and the cavernosal blood sample showed evidence of ischemic priapism. Given the presence of penile gangrene extending to the midshaft of the penis and the poor general condition of the patient, the decision was made to perform partial penectomy and suprapubic tube placement. We recommend the establishment of a guideline for the diagnosis and prevention of thrombotic diseases in patients with COVID-19 infection as there is increasing evidence of COVID-19-related thrombotic manifestations.
\end{abstract}

\section{Introduction}

A novel coronavirus (CoV) emerged in Wuhan, China, at the beginning of December 2019, named "COVID-19" by the World Health Organization (WHO) [1]. It causes a range of respiratory and gastrointestinal symptoms, including fatigue, cough, and fever that may progress to severe respiratory failure [2]. Other life-threatening complications include venous and arterial thromboembolism [3]. Pulmonary embolism (PE) is recognized as the most common thrombotic manifestation, while arterial events have been reported less frequently [4]. Priapism is considered a rare disorder [5] and even more rare when it occurs as a complication of COVID-19. To the best of our knowledge, only eight studies have reported priapism as a complication of COVID-19 [6-13].
Here, we report a case of a 66-year-old male with COVID-19 who presented with neglected priapism for three days and penile gangrene.

\section{Case Presentation}

A 66-year-old male patient presented to the emergency room (ER) with shortness of breath, cough, and generalized fatigue for two days; he tested positive for COVID-19 infection. However, he had a stable $\mathrm{O}_{2}$ saturation and was discharged accordingly. Five days following discharge, the patient represented to the ER with shortness of breath and neglected priapism of three days duration.

On his second ER visit, his $\mathrm{O}_{2}$ sat was $78 \%$ on room air, 92-93\% on $15 \mathrm{~L} / \mathrm{min}$ nonrebreather mask, blood pressure was $126 / 81 \mathrm{mmHg}$, respiratory rate was $21 / \mathrm{min}$, pulse rate 
was 110 beats per minute, and body temperature was $36.9^{\circ} \mathrm{C}$. His Glasgow Coma Scale (GCS) score was 15 out of 15 .

On examination, the patient was conscious and distressed. A priapism was observed together with blackened areas on the glans penis extending to the midpenile shaft denoting penile gangrene. A clear line of demarcation was noticed at the midpenile shaft.

The patient's medical history included type 2 diabetes mellitus (DM), hypertension (HTN), ischemic cardiomyopathy, and chronic kidney disease (CKD): stage $3 \mathrm{~b}$ with baseline creatinine $1.5-1.6 \mathrm{mg} / \mathrm{dL}$, atrial fibrillation, an old cerebrovascular accident (CVA) with no residual weakness apart from baseline expressive aphasia, and depression.

The patient's medications included amlodipine, insulin NovoMix, and hydralazine. He had also been taking warfarin $7.5 \mathrm{mg}$ once daily and risperidone $0.25 \mathrm{mg}$ and mirtazapine $30 \mathrm{mg}$ once daily as needed for the past five years.

Laboratory findings at admission showed leukocytes of $10.70 \times 10 \mathrm{e} 3 / \mathrm{uL} \quad(4.00-11.00), \quad$ hemoglobin $11.1 \mathrm{~g} / \mathrm{dL}$ (13.5-17.2), platelet count $220 \times 10 \mathrm{e} 9 / \mathrm{L}(150-450)$, prothrombin time (PT) $90 \mathrm{sec}(11.0-15.0)$, international normalized ratio (INR) $7.19(0.89-1.10)$, C-reactive protein (CRP) $219.50 \mathrm{mg} / \mathrm{L}(0.00-5.00)$, creatinine $244.20 \mathrm{umol} / \mathrm{L}$ (60.00-115.00), urea in serum $23.50 \mathrm{mmol} / \mathrm{L}$ (3.00-9.20), D-dimer $20.0 \mathrm{mg} / \mathrm{L}(0.0-0.5)$, and a positive COVID-19 polymerase chain reaction (PCR) test.

Penile duplex was performed and showed no blood flow in both cavernosal arteries. Magnetic resonance imaging (MRI) for the penis was requested to evaluate for necrosis but was unavailable in the hospital, and the patient could not be transferred due to his desaturation status.

2.1. Therapeutic Intervention. On admission, warfarin was withheld, and vitamin K $10 \mathrm{mg}$ IV was administered together with four units of fresh frozen plasma (FFP) to correct his elevated INR. He also received dexamethasone $6 \mathrm{mg}$ IV and ceftriaxone $2 \mathrm{gm} \mathrm{IV} \mathrm{infusions.} \mathrm{The} \mathrm{patient} \mathrm{was} \mathrm{then}$ admitted under the intensive care unit/internal medicine (ICU/IM) for further management of his COVID-19 infection and warfarin toxicity.

A suprapubic tube was placed to relieve urinary retention by the urology team, who further recommended penile aspiration/surgical intervention after INR correction. Later, in the same day, the patient developed hypoxia and was connected to high flow nasal canula (HFNC): FLOW 60, $\mathrm{FIO}_{2} 100 \%$, and stabilized. His INR had reduced from 7.14 to 1.70 , and anesthesia consultation was done for surgical approval.

The patient was taken to the operating theatre (OR), and as he was very agitated and a trial of a local penile block was not feasible, general anesthesia was introduced. Penile aspiration was performed, and the cavernosal blood sample showed evidence of ischemic priapism. However, penile aspiration was not successful to alleviate his erection. Given the intraoperative findings and the patients' poor general condition, it was decided to perform a partial penectomy.
Postoperatively, he was kept intubated and mechanically ventilated for three days, at which point he was successfully extubated. Eventually, he was discharged home with $\mathrm{O}_{2}$ maintained on room air.

\section{Discussion}

Priapism is a penile erection that lasts four hours or longer and is unrelated to sexual stimulation [14]. Priapism is grouped into three types: ischemic type (which requires immediate clinical intervention), nonischemic type, and stuttering (recurrent) priapism. Ischemic priapism (also known as venoocclusive priapism) is characterized by a painful penile erection which persists for a prolonged time leading to little or no blood flow to the corporal bodies [15]. Priapism can result from conditions associated with increased blood viscosity such as sickle cell disease and hematological malignancies [16], and hyperviscosity in patients with COVID-19 has been previously reported in the literature $[17,18]$, possibly accounting for the development of priapism in COVID-19 patients.

Moreover, COVID-19 is known to cause hypercoagulability although the underlying mechanisms for this are not well understood. Hypotheses include cytokine storm, complement activation, shutdown of fibrinolysis, and COVID-19 itself activating the coagulation cascade. Excessive release of cytokines causes thrombosis through a variety of processes, including the activation of monocytes, neutrophils, and the endothelium. All of these mechanisms can contribute to the prothrombic state $[4,19]$. It has been documented that COVID-19 patients can develop thrombotic events even when they are anticoagulated. Therefore, screening for thromboembolic events is essential in such patients [20]. In our literature review, we found eight cases of ischemic priapism, including one case of stuttering ischemia associated with COVID-19 infection (Table 1). Reported cases included patients ranging in age from 34 to 69 years, of whom one was also undergoing warfarin therapy, as in the current case. By comparison to our case, however, priapism did not progress to gangrene in any of the previously reported cases nor did any patient require surgery. No known risk factor for priapism was reported in four cases, and detumescence was achieved with an intracavernosal injection in five of the eight cases.

In our presented case, there were many risk factors for developing priapism other than COVID-19 infection, including unopposed warfarin action and antidepressant medication. However, it is only COVID-19 that had a recent onset in our patient compared to his long-term use of antidepressants and warfarin. Regardless of the cause, however, priapism rarely progresses to penile gangrene [21]. Other studies have also suggested that priapism was most likely induced by COVID-19 infection rather than other factors [6-8]. All of these evidences strongly suggest the need for the diagnosis and prevention of thrombotic diseases in at-risk patients with COVID-19 infection. 


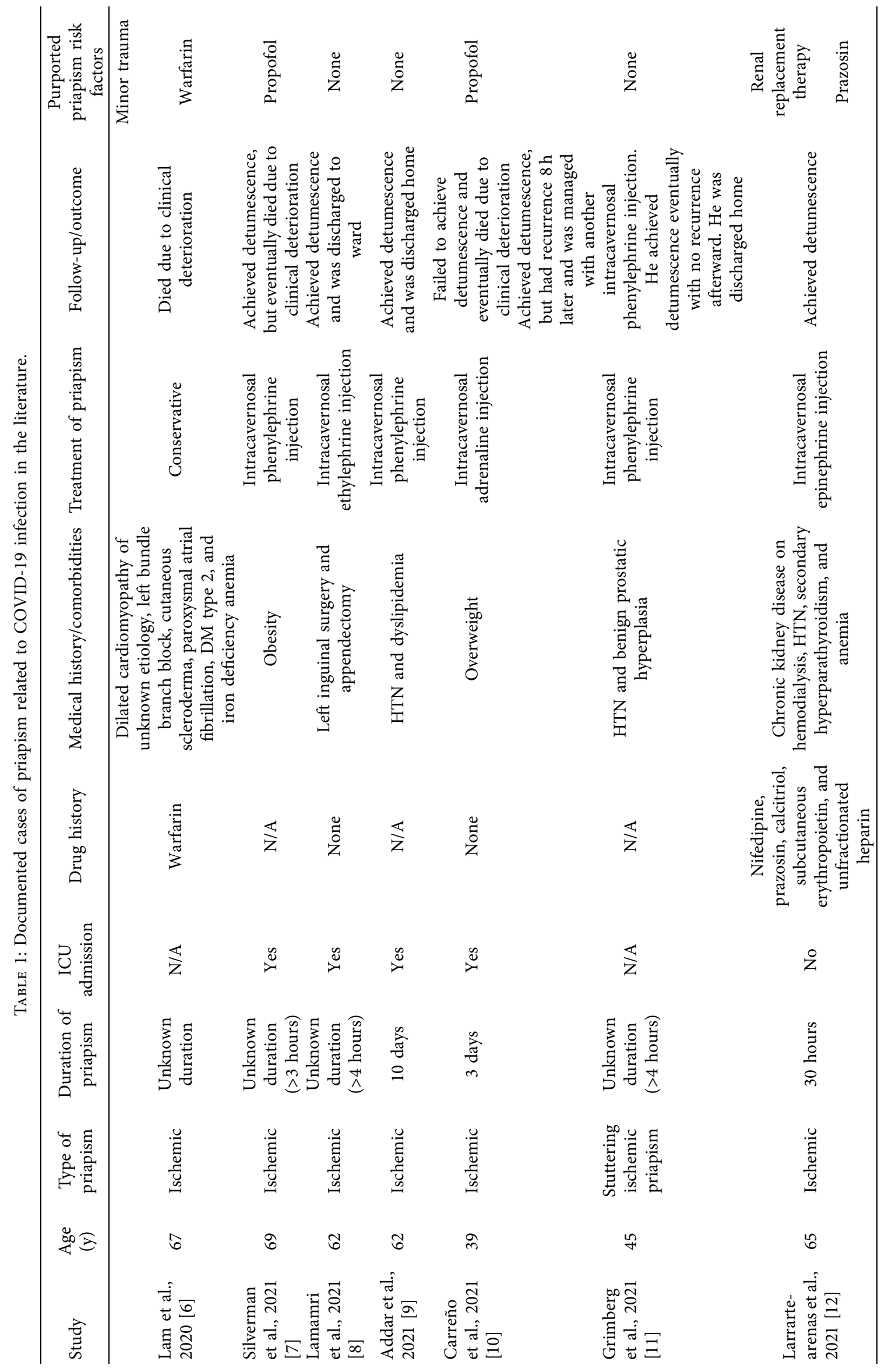




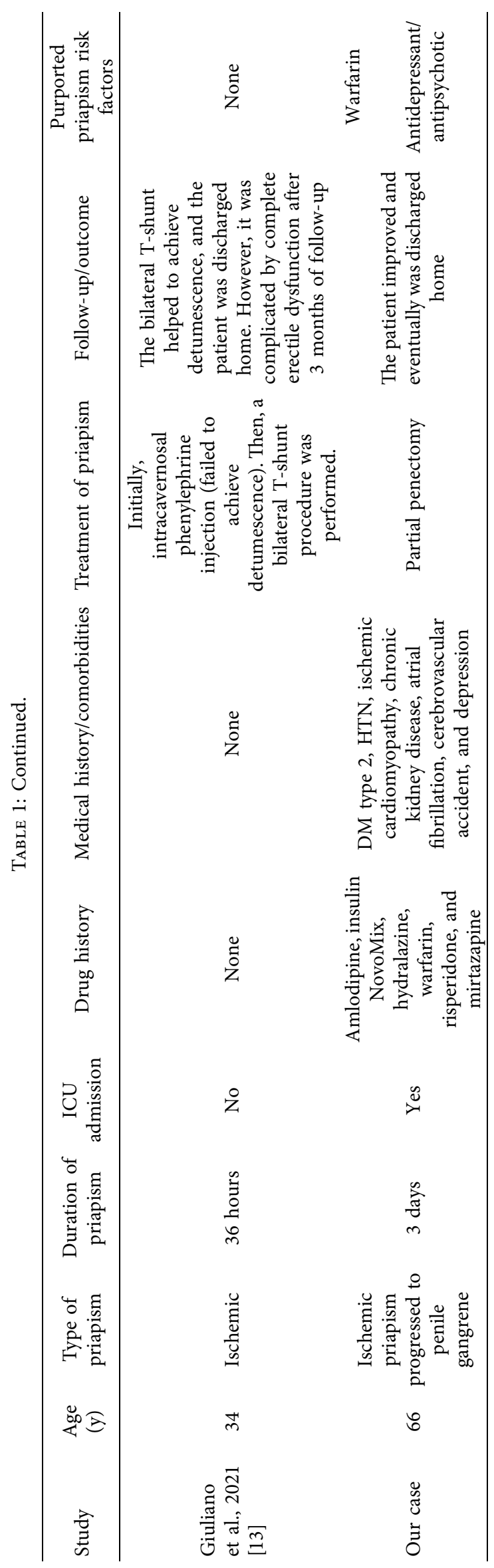




\section{Data Availability}

The data used to support the findings of this study are available from the corresponding author upon request.

\section{Consent}

All patient's identifying information is hidden and undisclosed. Consent was obtained from the patient for publication.

\section{Conflicts of Interest}

The authors declare that they have no conflicts of interest.

\section{References}

[1] 2021 https://www.who.int/news/item/29-06-2020-covidtimeline Listings of WHO's response to COVID-19 [Internet]. [cited 2021 Aug 9].

[2] S. Hamid, M. Y. Mir, and G. K. Rohela, "Novel coronavirus disease (COVID-19): a pandemic (epidemiology, pathogenesis and potential therapeutics)," New Microbes and New Infections, vol. 35, Article ID 100679, 2020.

[3] B. K. Tan, S. Mainbourg, A. Friggeri et al., "Arterial and venous thromboembolism in COVID-19: a study-level metaAnalysis," Thorax, vol. 76, pp. 1-10, 2021.

[4] M. Y. Abou-Ismail, A. Diamond, S. Kapoor, Y. Arafah, and L. Nayak, "The hypercoagulable state in COVID-19: incidence, pathophysiology, and management," Thrombosis Research, vol. 194, pp. 101-115, 2020.

[5] H. R. Levey, R. L. Segal, and T. J. Bivalacqua, "Management of priapism: an update for clinicians," Therapeutic Advances in Urology, vol. 6, no. 6, pp. 230-244, 2014.

[6] G. Lam, R. McCarthy, and R. Haider, "A peculiar case of priapism: the hypercoagulable state in patients with severe COVID-19 infection," European Journal of Case Reports in Internal Medicine, vol. 7, Article ID 001779, 2020.

[7] M. L. Silverman, S. J. Van DerVeer, and T. J. Donnelly, "Priapism in COVID-19: a thromboembolic complication," The American Journal of Emergency Medicine, vol. 45, no. 686, pp. e5-e6, 2021.

[8] M. Lamamri, A. Chebbi, J. Mamane et al., "Priapism in a patient with coronavirus disease 2019 (COVID-19)," The American Journal of Emergency Medicine, vol. 39, no. 251, pp. e5-e7, 2021.

[9] A. Addar, O. Al Fraidi, A. Nazer, N. Althonayan, and Y. Ghazwani, "Priapism for 10 days in a patient with SARSCoV-2 pneumonia: a case report," Journal of Surgical Case Reports, vol. 2021, no. 4, pp. 1-3, 2021.

[10] B. D. V. Carreño, C. P. Perez, D. Vasquez, J. A. Oyola, O. Suarez, and C. Bedoya, "Veno-occlusive priapism in COVID-19 disease," Urologia Internationalis, vol. 1-4, 2021.

[11] D. C. Grimberg, R. Tejwani, A. Allkanjari, M. T. Forrester, B. D. Kraft, and D. R. Kaye, "Ischemic priapism due to coagulopathy of severe COVID-19 infection," Journal of Clinical Urology, Article ID 20514158211025910, 2021.

[12] C. Larrarte-Arenas and D. C. Vargas-Ángel, "Priapism in a patient on hemodialysis and with COVID-19. Case report," Revista de la Facultad de Medicina: Scieloco, vol. 69, 2021.

[13] A. F. M. Giuliano, M. Vulpi, F. Passerini et al., "SARS-CoV-2 infection as a determining factor to the precipitation of ischemic priapism in a young patient with asymptomatic
COVID-19," in Case Reports in Urology [Internet], F. Koga, Ed., vol. 2021, Article ID 9936891, 3 pages, 2021.

[14] D. K. Montague, J. Jarow, G. A. Broderick et al., “American Urological Association guideline on the management of priapism," The Journal of Urology, vol. 170, no. 4 Part 1, pp. 1318-1324, 2003.

[15] Y.-C. Huang, A. M. Harraz, A. W. Shindel, and T. F. Lue, "Evaluation and management of priapism: 2009 update," Nature Reviews Urology, vol. 6, no. 5, pp. 262-271, 2009.

[16] A. Muneer and D. Ralph, "Guideline of guidelines: priapism," BJU International, vol. 119, no. 2, pp. 204-208, 2017.

[17] B. Joob and V. Wiwanitkit, "Blood viscosity of COVID-19 patient: a preliminary report," American Journal of Blood Research, vol. 11, no. 1, pp. 93-95, 2021.

[18] A. D. Truong, S. C. Auld, N. A. Barker et al., "Therapeutic plasma exchange for COVID-19-associated hyperviscosity," Transfusion, vol. 61, no. 4, pp. 1029-1034, 2021.

[19] A. Kichloo, K. Dettloff, M. Aljadah et al., "COVID-19 and hypercoagulability: a review," Clinical and Applied Thrombosis, vol. 26, 2020.

[20] J. F. Llitjos, M. Leclerc, C. Chochois et al., "High incidence of venous thromboembolic events in anticoagulated severe COVID-19 patients," Journal of Thrombosis and Haemostasis, vol. 18, no. 7, pp. 1743-1746, 2020.

[21] D. S. Nagathan, H. S. Pahwa, A. Kumar, and A. Goel, “Anticoagulant-induced priapism progressing to penile gangrene: a devastating complication," BMJ Case Reports, vol. 21, 2012 Available from: http://casereports.bmj.com/content/2012/ bcr-2012-007073.abstract. 